\title{
Crowdsourced mapping in crisis zones: collaboration, organisation and impact
}

\author{
Amelia Hunt and Doug Specht ${ }^{*}$ (D)
}

\begin{abstract}
Crowdsourced mapping has become an integral part of humanitarian response, with high profile deployments of platforms following the Haiti and Nepal earthquakes, and the multiple projects initiated during the Ebola outbreak in North West Africa in 2014, being prominent examples. There have also been hundreds of deployments of crowdsourced mapping projects across the globe that did not have a high profile. This paper, through an analysis of 51 mapping deployments between 2010 and 2016, complimented with expert interviews, seeks to explore the organisational structures that create the conditions for effective mapping actions, and the relationship between the commissioning body, often a non-governmental organisation (NGO) and the volunteers who regularly make up the team charged with producing the map. The research suggests that there are three distinct areas that need to be improved in order to provide appropriate assistance through mapping in humanitarian crisis: regionalise, prepare and research. The paper concludes, based on the case studies, how each of these areas can be handled more effectively, concluding that failure to implement one area sufficiently can lead to overall project failure.
\end{abstract}

Keywords: Crowdsourced mapping, Organisational structures, Networks, Humanitarianism, Crisis mapping, Volunteering

\section{Introduction}

The concept of crowdsourced crisis mapping is perhaps best defined as the provision of services by an international and/or online community, who gather, analyse and map critical information related to disaster-affected populations. Online digital responders often work as part of Volunteer and Technical Communities (V\&TCs) which offer free, technical services during, and outside of, humanitarian activations (Capelo et al. 2012). While there have been several explorations of crowdsourced mapping (Walker and Rinner 2013; Meek et al. 2014) and digital humanitarianism (Burns 2015; Meier 2015), this paper considers the current landscape of crowdsourced crisis mapping and the relationship between V\&TCs and formal humanitarian organisations. With crowdsourced crisis mapping becoming an ever more prevalent feature of emergency humanitarian response, the need for further research in this field is imperative. Thus far, existing literature has predominantly discussed the technology driving response mechanisms (Meek et al. 2014), with little detail on how technology has been

\footnotetext{
* Correspondence: d.specht@westminster.ac.uk
}

University of Westminster, London, UK adopted, nor the organisational strategies required to facilitate this. This paper focuses on the organisational nature of these projects, with attention paid to the collaboration between the technical and humanitarian fields, and the changing personal and organisational identities brought about by this global response mechanism.

This paper draws upon a series of high-level interviews to construct a broad impression of how these technologies, and their networks, have been mobilised across 6 years of crisis intervention (2010-2016). This approach seeks to understand the organisational structures required to effectively implement crowdsourced crisis mapping and highlight past points of failure. This research is predicated on two hypotheses, that (i) the context of crisis plays a more significant role than that assigned to it by VETCs and that (ii) the current level of collaboration across organisations remains inconsistent and inadequate due to poor preparedness strategies for analysing and utilising crowdsourced data. The paper, firstly, provides context to the emerging field of crisis mapping, before examining existing literature. The methodology is then introduced in more depth, before 
providing an overview of results, alongside a discussion examining the above hypothesis. Finally, recommendations are provided for improvements to the field of crowdsourced mapping.

\section{Background}

Within the humanitarian sector, crowdsourced mapping has arguably revolutionised the way in which crisis response is perceived, particularly through its ability to enable disaster-affected communities to define the way in which they receive help (Harvard Humanitarian Initiative 2011). Whereas historically, humanitarian organisations relied solely on field responders' assessments to calculate the relief needs of affected communities., the internet has, arguably, given voice to those in need, allowing them to project their needs to a global workforce of digital responders (Milner and Verity 2013). Although research has long discussed the virtues and limitations of crowdsourced maps for use in the non-governmental projects, humanitarian or otherwise (Specht 2016), it was the 2010 Haiti earthquake that brought the process of crowdsourced crisis mapping to the fore, and along with it a new research emphasis. During, and following, the earthquake, the Haitian population issued pleas for help using social media and...mobile technologies [and] around the world thousands of ordinary citizens mobilised to aggregate, translate, and plot these pleas on maps', an effort that was largely coordinated by the Humanitarian OpenStreetMap Team and Ushahidi, a crowdsourced mapping platform, using OpenStreetMap (Harvard Humanitarian Initiative 2011, p .8; see also Fig. 1).

Crowdsourcing entails the collecting of vast amounts of data from multiple sources to be processed at high speed (Anderson-Tarver 2015; Gao et al. 2011). This work is generally undertaken by Volunteers and Technical Communities, who are able to respond rapidly due to their decentralised global, non-hierarchical structures (GFDRR Labs 2011). For example, Moore and Verity (2014), note that nearly 230,000 tweets were gathered and processed within two days of Typhoon Haiyan hitting the Philippines' in 2013. This does not fall into the fallacy that some data is good and more is better (Junqué de Fortuny et al. 2013), as only 800 of these tweets provided emergency responders with relevant, actionable data. While this represents just $0.35 \%$ of twitter-sourced information collated by the crowd, the quick sifting of data highlighted key areas of destruction and potentially saved lives.

Although limited actionable outcomes resulted from the above case, it demonstrates that technology now allows global citizens to engage more closely with the causes that matter to them as individuals without the barriers of geographical distance. This results in the

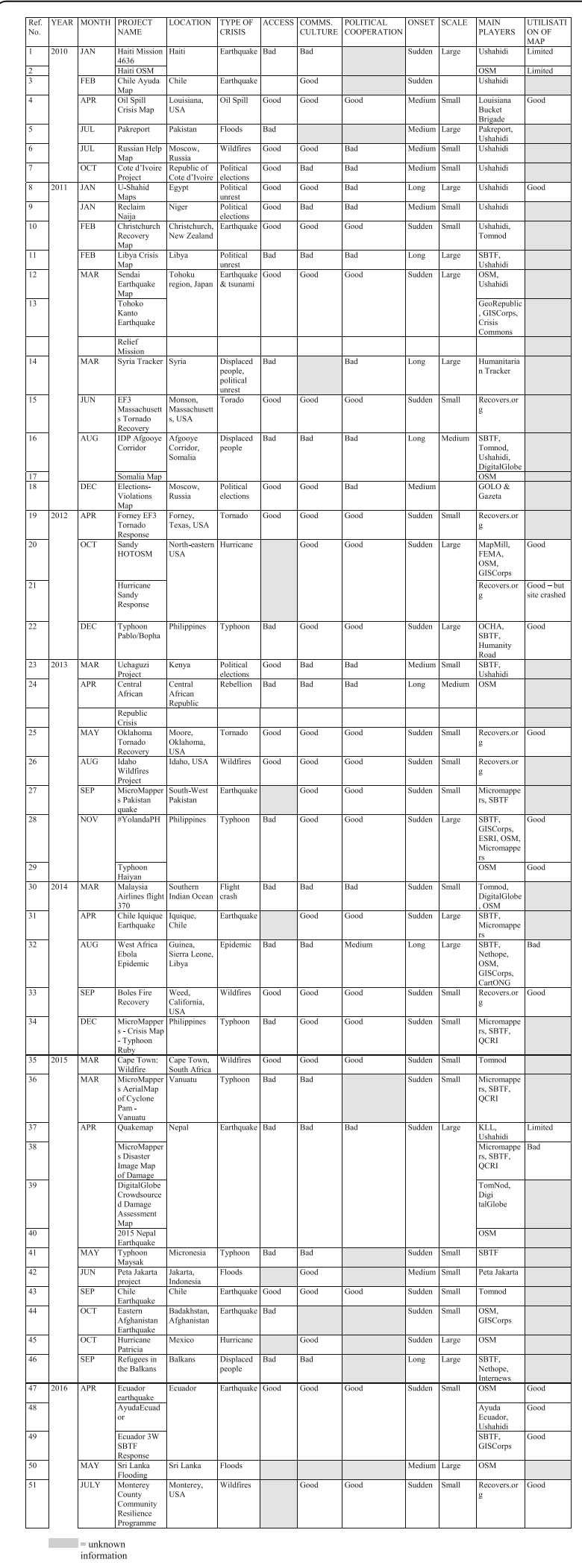

Fig. 1 Crisis contexts of crowdsourced mapping based on Kuryak (Interview 2016), Link (Interview 2016), Meier (Interview 2016) and Moore (Interview 2016) 
formation of international networks united by shared beliefs and equipped to participate in online collective action (Sancho 2014). This has already altered the humanitarian landscape, and while formal humanitarian entities continue to be the mainstay of crisis efforts, they are no longer the sole players in the humanitarian sphere. Rather, the internet provides the general population a means to self-organise and participate as volunteers, often as part of V\&TCs (Stadler 2012).

The degree to which online volunteering has taken place has grown substantially, with 51 significant deployments of V\&TCs responding to crises between 2010 and 2016. Yet, despite increasing calls for this kind of deployment, particularly from information management specialists, there is currently little analysis of the impact these processes have had on humanitarian organisational structures. Furthermore, despite multiple reviews and reports on the technological advances that could make crowdsourced crisis mapping a valuable humanitarian tool, there have been limited investigations as to how this might integrate within traditional humanitarian frameworks, cultures and working patterns. Plans for the future of crowdsourced crisis mapping, both during a crisis, and in crisis preparedness, remain loose and varied.

\section{Review of literature}

Within a crisis, crowdsourced mapping allows geotagged digital photos, aid requests posted on Twitter, aerial imagery, Facebook posts, SMS messages and other digital sources to be collected and analysed by multiple online volunteers (MicroMappers 2016). This data is then cross-checked by other volunteers to give insights as to the severity of a needs request. This validation process gradually builds an understanding of the damage in an area and helps responders focus on those in need. Maps built from crowdsourced data of disaster-affected populations offer unprecedented depictions of communities needs within a crisis. Furthermore, communitysourced intelligence is generally considered to be 'fresher and more accurate than the information given to the responders who provide aid' (Plantin 2014, p. 13). By generating maps using information sourced from multiple outlets, such as social media, news reports, SMS messages and satellite imagery, a rich impression of an emergency situation can be generated by the power of 'the crowd'. In their studies of the 2010 Haiti earthquake, Nelson and Sigal (2010) conclude that there is substantial evidence to advocate the use of crowdsourced mapping to improve emergency response; maps built from crowdsourced data, they stated, had the potential to better inform humanitarian response efforts in aid provision and provide a basis for post-disaster reconstruction. The Harvard Humanitarian Initiative (2011) has also suggested that traditional response systems can be enhanced by the inclusion of digital volunteers. Harvard Humanitarian Initiative (2011) describes the online need requests from victims of the 2010 Haiti earthquake as a surge of collective intelligence. This collective intelligence, once processed by digital volunteers, resulted in the production of tangible needs assessment maps for responders.

Despite the potential of the online crowd, crowdsourced mapping is not a silver bullet, debates around inclusion and representation still rage (Kidd 2015) and there is evidence that crowdsourced crisis mapping projects are often confronted by organisational issues. Following the 2010 Haiti earthquake, Nelson and Sigal (2010) suggested that there was a need to increase 'reliability, professionalism [and] recognition of humanitarian principles' (p. 23) within V\&TCs, as well as to improve learning and awareness within the professional humanitarian sector. They note that despite an outward openness shown by traditional organisations towards new technologies, there was an overriding fear of the repercussions of outsourcing crisis data collection and the consequences of using data sourced from social media. Issues of trust, reliability and technical consistency that arise in the utilisation of alternatively sourced data (Goodchild and Glennon 2010; Patrick 2011), leading to slow cooperation in information sharing following the 2010 Haiti earthquake. Munro (2012) notes that a wealth of information created by local Haitian communities was lost due to the subsequent inability of most humanitarian organisations to utilise 'engage the crisis-affected community directly' (p. 256). These issues were still not addressed in 2015 when another earthquake struck Nepal, again detailed crowdsourced data was dismissed because of a lack of organisational infrastructure, and humanitarian politics (Ramalingam 2016). Moore et al. (2016) also found that bureaucracy, and apprehensions over cross-organisational information sharing, led to humanitarian information management failures.

Much of the crowdsourced data collected during moments of crisis do not get processed directly by the humanitarian sector. Instead, Volunteer and Technical Communities (V\&TCs) play a major role in the processing and codification of this information. However, the relationships between V\&TCs and formal organisations are often built upon inconsistent, personal connections between players (Nelson and Sigal 2010). These formulations lead to significant collaboration issues between V\&TCs and formal responders, an issue identified as a cultural divide (ibid.). This collaborative barrier is further compounded by a prejudicing of innovation over integration, with a culture of seeking new ways of doing things taking precedence over integrating techniques across the sector (Munro 2012). Sharma (2010) also 
suggests several factors influencing a crowdsourced projects' success, mirroring the call for more collaboration and trust, but also adding the need for a clear approach and a united goal. While the charitable aims of V\&TCs donating their time are apparent (Meier 2015), a crisis context collaborative strategy, such as partnership packages, between formal and informal entities needs to be considered (Milner and Verity 2013). Despite previous recommendations from Harvard Humanitarian Initiative (2011) to resolve traditional-digital collaboration concerns by undertaking joint investigations into best practices, pushing field responders to utilise innovative tools, and establishing structured approaches to crossorganisational communications, little has been done to realise these suggestions. These issues are best summarised by Bott and Young's (2012) recognition that 'both the strength and weakness [of crowdsourced mapping] ...derives from its participatory openness' (p. 56). While technology allows us to capture information directly from disaster-affected communities, it raises the problem of how to process these vast additional datasets, and by whom the potentially enormous task should fall to, to ensure data can be verified and privacy rights are ensured.

The humanitarian sector now faces a data deluge (UNGP 2012), a stark contrast to the single-sourced, one-directional data previously collated by humanitarians. While this data has huge potential to improve targeted response plans, without adequate filtering and processing solutions, the new data presented is unusable. Even with technological innovation, the processes involved in extracting pertinent crowdsourced information during a crisis are laborious (Heinzelman and Waters 2010). This places enormous pressure on V\&TCs participants as they seek data accuracy. The validity process of crowdsourced data is further exacerbated by the tendency of private corporations, governments and formal humanitarian departments to withhold datasets that could help V\&TCs to assess their data (UNGP 2012; Meier 2015). Thus, it might be assumed that improvements to information management processes and data standards could be key in overcoming the inability of existing humanitarian systems to process and utilise data crowdsourced using alternative methods (Anderson-Tarver 2015). Yet there still persists the notion that technologies are progressing faster than people can adapt to effectively utilising them (Deuze 2012).

While crowdsourced data itself might be underutilised, the crowdsourcing process has already impacted the humanitarian sector. Stauffacher et al. (2012) sees crowdsourcing as a 'means through which to verify existing information, improve accountability [and] increase the effectiveness of humanitarian operations' (p. 4). Crowdsourced data has already challenged organisational accountability and operational effectiveness. Crowdsourced mapping has disrupted traditional humanitarian processes and opened conversations to include multiple stakeholders, from local community members, to field responders, to remote V\&TCs. Crowdsourcing as a methodology, utilised or not, raises questions around open data sharing, cross-organisational collaboration, common objectives and digital communication methods in response to crises. These questions, and the potential answers they present, have already begun to disrupt the traditional 'top-down' flow of power within some organisations, creating a more organic, connected configurations (Meier 2015). Brafman and Beckstrom's (2006) observations of open systems within the public sector aptly reflect those within the evolving humanitarian system; 'an open system doesn't have central intelligence; the intelligence is spread throughout the system' (p. 39).

Problems arise though when one attempts to apply these models to highly centralised organisations. As Brafman and Beckstrom (2006) posit in their 'spider structure' theory-'when attacked, centralised organisations tend to become even more centralised' (p. 139). Humanitarian organisations are already increasingly under 'attack', with tightening budgets and the increasing frequency of humanitarian crises. This can halt information distribution and prevent cross-organisational collaboration, blocking the dissemination of crowdsourced data and hindering investigations around progressive digital response methods. As Tapscott and Williams (2010) note, 'organisations that make their boundaries porous to external ideas and human capital outperform those that rely solely on their internal resources' (p. 56).

Given the potential for improving humanitarian systems through crowdsourced data as noted above, it is perhaps imperative to examine how organisation structures within the sector are blocking usage of such data. The remainder of this paper will examine a series of organisations and crises between 2010 and 2016, in order to explore appropriate working methods for the future.

\section{Methods}

This research draws primarily upon interviews, with some light document analysis used to provide context to each of the events discussed. Purposive sampling was used to identify respondents from both formal humanitarian organisations $(n=5)$ and from volunteer and technical communities $(n=5)$. The interviewees were drawn from a diverse group of practitioners who had worked on crisis response across the globe, including the Ebola epidemic (2014), the 2015 Nepal Earthquake, Vanuatu Typhoon (2015) and the 2010 Haiti Earthquake (see Table 1). These interviews helped ascertain the nature and actions of the organisations and communities and gave insight into how they see the role of crowdsourced 
Table 1 List of interviewees and their respective organisations

\begin{tabular}{|c|c|c|}
\hline Name & Role & Organisation \\
\hline Roxanne Moore & -Product and DHN support & -United Nations Office for the Coordination of Humanitarian Affairs \\
\hline John Sabou & -Research fellow & -Institute for Security and Global Affairs, Leiden University \\
\hline Neil Horning & -Nepal digital humanitarian coordinator & -Digital Humanitarian Network \\
\hline Andrej Verity & $\begin{array}{l}\text {-Information officer, field information services. } \\
\text {-Co-founder of digital humanitarian network }\end{array}$ & $\begin{array}{l}\text {-United Nations Office for the Coordination of Humanitarian Affairs } \\
\text {-Digital Humanitarian Network }\end{array}$ \\
\hline Yaelle Link & -Information officer, field information services & -United Nations Office for the Coordination of Humanitarian Affairs \\
\hline Katie Whipkey & -Freelance consultant in public policy & Freelance \\
\hline Andrew Braye & -GIS team facilitator and corporate reporting & -British Red Cross \\
\hline Simon Johnson & -GIS technical lead & -British Red Cross \\
\hline Patrick Meier & $\begin{array}{l}\text {-Co-founder of digital humanitarian network executive director } \\
\text {-Co-founder of WeRobotics } \\
\text {-Founder of Humanitarian UAV Network }\end{array}$ & $\begin{array}{l}\text {-Digital Humanitarian Network } \\
\text {-WeRobotics } \\
\text {-Humanitarian UAV Network }\end{array}$ \\
\hline Chris Kuryak & -Chief operating officer & -Recovers.org \\
\hline
\end{tabular}

crisis mapping in crisis response missions. The in-depth interviews were semi-structured in nature, and comprised of a series of standardised themes relating to organisational structures and failures, as well as seeking recommendations for the sector. Document analysis, examining the reports produced around each crisis, helped give context to each crisis and the responses provided in the interviews.

\section{Results}

The results presented follow the two given hypotheses; 51 crises between 2010 and 2016 were documented (see Fig. 1) and categorised in relation to their severity (based upon loss of life and infrastructure), type of response, responders and the conditions under which this response took place (based on telecommunications, and government structures); these were then used to corroborate responses from interviewees.

\section{Context}

It was posited that the context of a crisis will play a significant role in the forming of a response by Volunteer and Technical Communities (V\&TCs), and by extension this leads to V\&TCs providing support that is not sufficiently context driven and nuanced as professional humanitarians might need.

The results show a correlation between the context of the crisis and the relative utilisation of V\&TC generated maps in their response. In regions, such as Louisiana, USA, Egypt, the Philippines and Ecuador, where the communications culture is rated as good, mapping responses are also rated as good. Conversely, in regions where the communications or access rating is noted as poor-Nepal, Sierra Leone-mapping responses are correspondingly rated as poor (see Fig. 1). These ratings, while subjective, are based upon evidence from interviewees, and offer a degree of context to which other results can be related.

One theme particularly pertinent to the utilisation of crowdsourced mapping methods was the political environment of an emergency. Multiple interviewees (Link, Interview 2016; Verity, Interview 2016) highlight the difficulty and dangers of using crowdsourced methods in the context of repressive regimes amidst atmospheres of fear and reservations towards open data. Although Fig. 1 suggests that even in examples where democratic governance is present, the attitudes of a nation's government towards technologies, innovation and open data standards has an impact on the implementation of crowdsourced data.

\section{Collaboration and preparedness}

The second hypothesis is that levels of collaboration remain inconsistent due to a lack of preparedness within both parties. While some of this is due to changing context, lack of preparation was fundamental to formal responder's willingness to corroborate with V\&TCs. Principle concerns revolved around prior awareness of V\&TC, the extent of their capabilities and their legal standing. Although awareness and promotion of the benefits of crowdsourced crisis mapping has increased, inter-organisational structures between those supplying crowdsourced mapping data, the V\&TCs and their intended 'clients', and formal responders, are still in their infancy. This is a notion corroborated by Sabou (Interview 2016) and Roxanne Moore (Interview 2016), researchers examining the DHNetwork, who both point to a growing tension between traditional organisations and digital responders around notions of legitimacy. These tensions have been exacerbated as V\&TC's discuss providing crowdsourced crisis maps directly in partnership with local governments or militaries, rather than humanitarian entities (Sabou, Interview 2016). 


\section{Discussion}

The results suggest that in acute emergencies, a lack of time or space to assess data leads to new and untested data sources, such as crowdsources mapping, are the first to be dismissed. Andrej Verity, a UN OCHA information officer, recalled the first-time crowdsourced mapping came to his attention during the Haiti earthquake in 2010:

The Ushahidi 4636 crisis map hit my inbox and at that time, with the work that we had, I looked at it, said 'this is interesting, a gold mine of data, but too unstructured and loose for us to do anything with at this time'. And so, I wrote an email 'investigate out of Haiti' (Verity, Interview 2016).

Similar reports shortly after the Haiti crisis from the Harvard Humanitarian Initiative (2011) asserted that the lack of a formal contact point with the V\&TCs only served to overwhelm overworked responders managing data within a fast-changing situation. Entities, such as the DHNetwork, prove that a successful operation requires a set of partnerships. The DHNetwork is a leaderless umbrella group coordinated by an annually rotating body of four volunteers from one of their partner organisations, who are obliged to act objectively as a representative of the entire consortium (DHNetwork 2016). Rather than fulfilling a leadership role, the coordinators are tasked with responding to activation requests made by external organisations requiring specialist assistance in an emergency and matching these requests to the appropriate DHNetwork partner group (DHNetwork 2016). Many open source humanitarian communities are adopting similar distributed models.

Throughout the research, this leaderless structure of the DHNetwork produced varied responses. Many respondents suggested that the establishment of a formal entity, or the formalisation of the DHNetwork, could ease collaboration between traditional organisations and digital players, and advocated for the creation of a legal entity with paid coordinators. Formalisation could open channels for funding and improve the credibility of V\&TCs (Link, Interview 2016). Despite the potential benefits of moving away from a peer-to-peer open network structure, Braye (Interview 2016) stressed the danger of preventing cross-organisational collaboration with unnecessary institutional barriers.

These issues raised over half a decade ago are still apparent today. Link (Interview 2016) expressed how problematic additional data integration can be amid a crisis for responders who are already overstretched in their day-to-day tasks. Emergency responders also held expectations surrounding the data they were willing to accept, principally based on past experiences or data presented by reliable humanitarian 'brands' (Verity, Interview
2016). Furthermore, the data required varies dramatically across crises, and often, during sudden onset emergencies, responders are unsure of their immediate information needs. This makes it difficult to predict whether crowdsourced data is immediately useful and usable (Link, Interview 2016). It is perhaps understandable then that crowdsourced crisis mapping, despite providing a wealth of additional information, cannot automatically and effortlessly be utilised within demanding, unstable contexts. In contrast, there are contexts where there is such minimal data available to emergency responders, that any data, regardless of the stressful context, becomes highly valuable (Link, Interview 2016).

The increased use of open data sharing, free flow information and collective participation are all strongly ingrained into the practice of crowdsourced crisis mapping. These characteristics are part of an emergent pattern of open movements including the Open Source Initiative, Open Data movements (Stauffacher et al. 2012) and Open Humanitarianism. However, these do not fit well with present structures within the humanitarian sector leading to the adoption of crowdsourced mapping methods for personal use (Verity, Interview 2016). Following the 2015 Nepal Earthquake, many digital responders were disheartened to learn that the crowdsourced maps they had created were not utilised in the crisis. Meier, founder of DHNetwork, (Interview 2016), like Verity, attributed the failed utilisation to individuals. Often, it is the personal opinions of leading in-country responders, which determines the application or dismissal of crowdsourced data. Meier contrasts the Nepal experience with the openness of leading responders during the Libya crisis, and the subsequent integration of crowdsourced crisis maps at a formal level of UN management. As Link, an information officer with UN OCHA (Interview 2016), highlighted, the difficulties with sharing data, even at an inter-organisational level, are compounded due to concerns over privacy and security. Similar observations were made by Specht (2016), noting a clear lack of internal openness within formal organisations, and even more restrictive processes in inter-organisational settings. Whipkey (Interview 2016) also highlighted concerns of responders in trusting unverified information, particularly in the current climate where the financial input of donors is often precarious and formal leaders are unprepared to consider the additional risks of external collaboration.

Despite the prevalence of top-down hierarchical structures in formal humanitarian organisations, there are growing numbers of individual connections between players at various levels of this hierarchy (Braye, Interview 2016). A move towards remote, global working has also contributed to this shift. As seen in Fig. 2a, increased distribution of information and power within an organisation reaches 

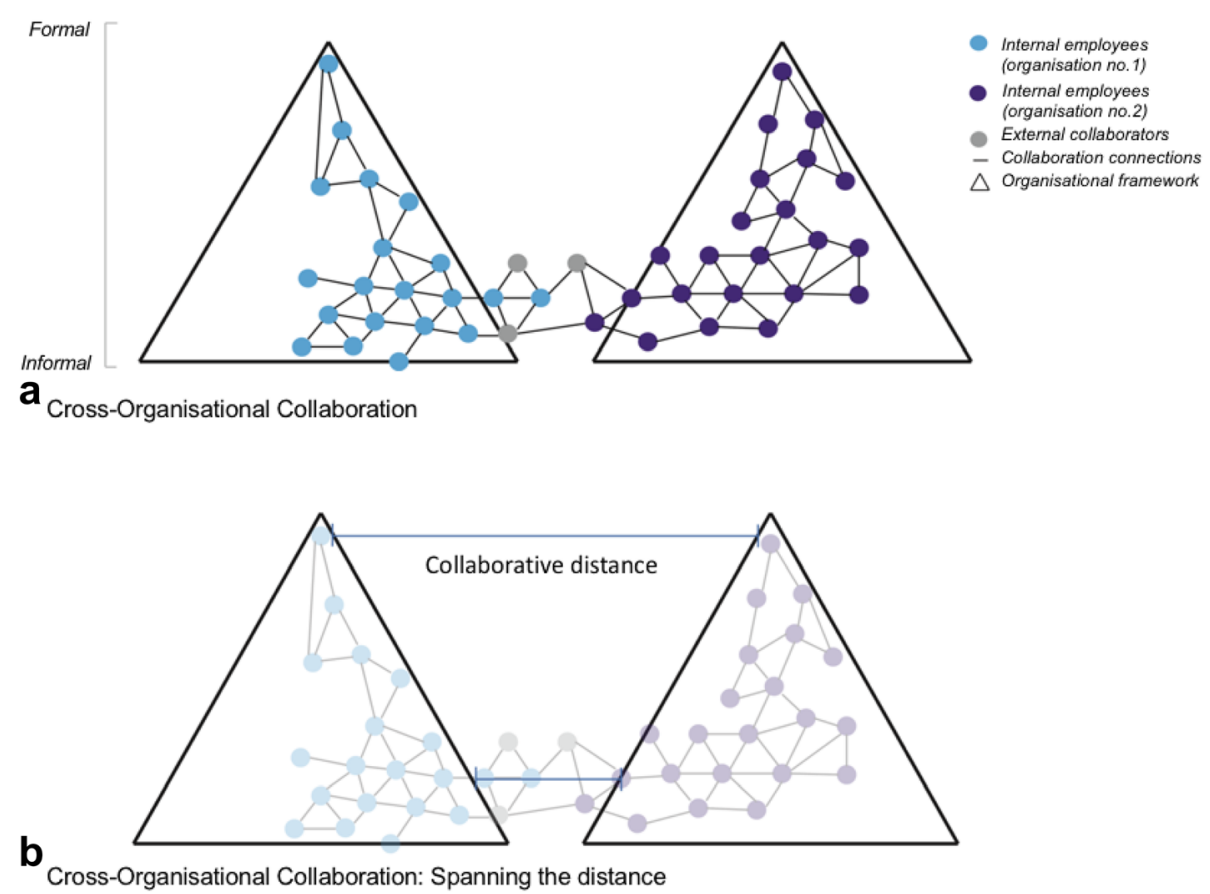

Fig. 2 Cross-organisational collaboration, and collaborative distance. Derived from Braye (Interview 2016) and Johnson (Interview 2016)

beyond the organisations' own internal framework, might allow for cross-over with external partners.

The benefits of this structure become apparent when the relational distance between humanitarians is applied (Fig. 2b), with cross-organisational links formed by personal connections, trust and credibility (Braye, Interview 2016; Sabou, Interview 2016). Johnson, GIS lead at BRC (Interview, 2016), highlights the ease at which cross-organisational collaboration could be facilitated through personal connections as opposed to over-reliance on formal institutional procedures.

Considering the importance of cross-organisational collaboration, Chris Kuryak, COO of 'recovers.org' (a free website for organising and mapping disaster relief), describes the initial issues arising with the platform 'recovers.org' due to the lack of organisational engagement (Kuryak, Interview 2016). The involvement of organisations acting as connecters across the public and digital sphere helped facilitate need responses and allowed them to make themselves more visible to affected communities (Kuryak, Interview 2016).

These results suggest that it is not technology which is the issue, but collaboration and context, both of which are hindered by a lack of preparedness. As new methods, such as crowdsourced crisis mapping, have emerged in the humanitarian sphere, a principle difficulty is how to connect and facilitate the information and task sharing across the technical and humanitarian spheres. Interviews revealed that it is not always an unwillingness to embrace new technology, but that coordination and cooperation are needed. In addition, the study reveals that collaborative issues are not solely the result of bureaucracy, but also security, context and personal beliefs.

\section{Recommendations}

A consistent array of issues has emerged around the application of crowdsourced crisis mapping, principally a lack of collaboration and communication amongst formal and digital responders and a lack of understanding on when and why to utilise crowdsourced data. Considering the future of crowdsourced crisis mapping within the humanitarian sector, numerous recommendations and solutions arose from participants. These solutions, drawn from the issues raised, have been categorised by the authors into three key areas: (a) regionalise, (b) prepare and (c) research. This discussion will take each of these, in turn, before offering a summary of the findings and a conclusion to this work.

\section{Regionalise}

A lack of contextual understanding was seen as a considerable barrier to the use of crowdsourced data, including misunderstanding of the socio-cultural and geographical context of a crisis, and the type and scale of emergency. For example, the 2016 Ecuador earthquake and the 2015 Nepal earthquake both attracted a great number of Volunteer and Technical Communities (V\&TCs), yet despite some similarities in crisis type, the success in integrating crowdsourced data varied greatly. Link and Moore (Interviews 2016) attributed the success 
of crowdsourced mapping in Ecuador to the smaller scale of the earthquake, preparedness on the ground and pre-established connections between formal responders and V\&TCs which were not present in Nepal, where field responders had limited time and resources to deal with extra datasets.

Therefore, a common recommendation amongst humanitarians has been the regionalisation of digital responses (Verity; Meier; Kuryak; Link, Interviews 2016). If significant contextual research was invested in areas more susceptible to natural disasters and in which there is a substantial communications infrastructure, it could prove beneficial to invest more in upskilling local communities with digital skills or establishing local digital humanitarian hubs. These could potentially act as subsets of the digital humanitarian network (Verity, Interview 2016). By localising digital response efforts, digital responders could connect and engage with communities before a crisis, creating a bank of local geographical and organisational knowledge. In a crisis, this pre-established local knowledge and face-to-face presence of digital responders could increase credibility and validity, providing formal responders with a valuable incentive to utilise crowdsourced crisis maps (Link; Verity, Interviews 2016). Sabou suggested (Interview 2016) that this approach would help resolve existing difficulties of UNOCHA's attempts to plug in DHNetwork's capacities at a local level. Meier (Interview 2016) notes the rapid mobilisation of local V\&TCs following Typhoon Haiyan in 2013. If cross-organisational partnerships were formed before a crisis, crowdsourced data could integrate more fluidly across the response system when a crisis hit due to existing communication channels (Verity and Whipkey 2015). If more contextual research was undertaken and regionalised crowdsourced mapping efforts increased, a greater level of disaster preparedness could be established. Particularly as technology to predict natural disasters improves, local and international V\&TCs should be involved in pre-disaster planning (Meier; Kuryak, Interviews 2016). These efforts could also reduce the risk of Western-centric interpretations of community needs being enforced and creating dependency patterns, as has been the unfortunate result of some technologies within the development sector.

\section{Prepare}

Building upon the above ideas, Sabou (Interview 2016) notes that disaster preparedness relies on a networking system that currently does not exist. In instances where communities have built networks and been trained in software before a crisis, smoother response operations have been noted (Kuryak, Interview 2016). Indeed, statistics suggest that for every $\$ 1$ spent on disaster preparedness, $\$ 4$ is saved in the disaster itself (FEMA 2016). This statistic could prove even more consequential for crowdsourced mapping, for which pre-mapped access routes and medical facilities could save both lives and time as well as money, as demonstrated by the work of the Humanitarian OpenStreetMap Team (HOTOSM) in their work in Haiti to prepare for further crisis' following the initial response to the 2010 earthquake (Soden and Palen 2014).

Despite the seemingly obvious benefits of disaster preparedness, Kuryak (Interview 2016) attributes the failure of their own preparedness experiment 'ready.recovers.org' to the human psyche. Based on the platform 'recovers.org', a free website for organising and mapping disaster relief, 'ready.recovers.org' attempted to gather community data preceding a crisis but it was met with disinterest. As Kuryak explains (Interview, 2016), despite multiple investigations into the 'psychology of preparedness', there are limited conclusions on which triggers incite people to prepare effectively.

The lack of international media focusing on at-risk communities often diminishes the sense of urgency to support preparedness efforts (Verity, Interview 2016). Crowdsourced mapping during a pre-crisis context could overcome many of the major challenges presented within a disaster itself such as pressure, timeframe and validity (Meier, Interview 2016), but as Whipkey (Interview, 2016) stated, 'it's easier to write about instances where data could have been useful in preventing a crisis, than to actually put the steps in motion'. Preparedness should not be seen as an extra expenditure within the humanitarian sector. Preparedness needs to be re-evaluated as an investment towards more efficient, cost-effective response networks for when disaster hits. Programmes, such as Missing Maps, attempt to engage volunteers with preparedness efforts by highlighting their role within the larger crisis response chain. Reimagining maps as 'pre-crisis maps' or perhaps 'dormant crisis maps' is another possible solution. When crowdsourced crisis maps exist outside of the actual crisis, with base layers generated pre-crisis so that only damage extent data needs to be added during the crisis itself, the effectiveness and utilisation of these maps can be better guaranteed. Mind-sets towards preparedness need to change so that crowdsourced mapping can be integrated earlier into the humanitarian response cycle.

\section{Research}

Regionalisation and preparedness would benefit from better, in-depth research and feedback loops, a change that Neil Horning, of the Digital Humanitarian Network (Interview 2016), believes could improve data quality and analysis during crises. Rather than seeking ever newer solutions, working models can be improved through establishing data standards, enabling crisis information to be presented in a digestible way (Horning, Interview 2016). This would improve 
formal organisations willingness to utilise new data sets from V\&TCs. It is no longer sufficient to write retrospective crisis reports, rather humanitarian processes need to include ongoing analytics and data manipulation, providing up-to-date feedback to data providers (Moore et al. 2016). Researchers can play an imperative role in evaluating new innovations in real-time to provide comprehensive crisis analysis (Verity and Whipkey 2015). Thus far, despite admirable efforts of DHNetwork to connect digital organisations and bridge the technical and humanitarian divide, there is little evidence as to the success of this endeavour (Meier, Interview 2016).

Beyond this, the humanitarian sector needs to improve transparency and research into failure. While funding for research is a major issue, the reluctance to investigate failures within the humanitarian sector appears to root itself in psychological, not financial, factors. Kuryak (Interview 2016) explains the psychological pressure of organisations to meet donor expectations or risk losing funding. Meier (Interview 2016) concedes that following the Nepal earthquake, the 'failure' of crowdsourced maps to be utilised was deliberately not advertised so that volunteers that had dedicated so much of their time would not be disheartened. Moore, Bhide and Verity's correlation of 'failure' to fatalities makes apparent the concerns of some humanitarians to analyse failures and take accountability (2016). When failure equates to lives lost, there is a reason failures are not discussed. Past crowdsourced mapping operations, those utilised by responders or not, deemed successes or failures, need to be analysed to improve crowdsourced data processing, validity, formatting, sharing, utilisation and feedback.

\section{Summary}

The emergence of crowdsourced crisis mapping in an era of social media, web forums and blogging does not take away fundamental human instinct for interaction, and people are not yet adept at building online working relationships, relying more on offline connections (Verity, Interview 2016; Ardichvili et al. 2003). Face-to-face connections facilitate trust and collaboration (Link, Interview 2016). This does not, however, mean the abandonment of digital crisis response because of a human predisposition to trust those humanitarians working in the field. Instead, whether in-person or online, partnerships, like emergencies, need, as outlined above, a level of preparedness. 'Those V\&TCs that successfully collaborated with the formal humanitarian system were those that developed relationships prior to crisis' (Milner and Verity 2013, p. 47). The midst of a crisis is not the time in which to establish communication structures for information sharing, nor is it necessarily one in which it is appropriate to build comprehensive relationships. Compromise is essential for the traditional and digital humanitarian sectors to adapt their networking structures to facilitate collaboration through transparent information sharing, data standards, joint impact measurement and constructive, proactive discourse. V\&TCs may well have a pivotal role in the humanitarian sector, whether that is for emergency response or development of a carefully calculated formula of the two. Time and effort needs to be invested in structures in which the power of the online crowd can be utilised by formal organisations through intermediary offline connections. Coordinators from the technological and humanitarian sphere need to be engaging in dialogues to ensure better accuracy of crowdsourced data through the introduction of open data policies and verification strategies (Sabou, Interview 2016; Horning, Interview 2016). Technology is generally advancing faster than the human capacity to adapt (Link, Interview 2016; Dodd 2015; Deuze 2012), it is therefore imperative that common ground is found between V\&TCs and formal humanitarian agencies to facilitate effective use of these digital tools.

\section{Conclusion}

This research has highlighted barriers to collaboration across the humanitarian and digital spheres. Concerns over secure data sharing, collaboration within stressful emergency contexts, a fear of unsettling established bureaucratic procedures, personal reservations around new technologies and a lack of preparedness are just some of the issues preventing the maximum utilisation of crowdsourced mapping. While there have been efforts made in some cases to address these (see Soden and Palen 2014), there remains a dramatic contrast between the concrete, organisational structures of formal humanitarian networks and the fluid, open structures of V\&TCs creating significant obstacles to effective communication, coordination and collaboration.

As Kim Scriven (2016) writes, as innovation efforts reach fruition, it will become increasingly important to demonstrate their impact at both the project and system level'. Similarly, in describing the demanding role of assessment analysts directly following a disaster, Verity (Interview 2016) suggests that overstretched assessment personnel need to be supported by long-term academic studies. Human nature also stands in the way of methods which have not been yet proven as effective, and, despite the increased use of crowdsourced crisis mapping in the years since the 2010 Haiti Earthquake, little formal evaluation of effectiveness has been made. The reputation of digital responders is changing, but it could take many years and multiple crises before digital humanitarians are sufficiently accredited and the data they bring with them can be utilised.

The political context of a crisis also has a strong bearing on the cooperation between governments, formal organisations and V\&TCs, and can greatly impact the process of data verification from dependable records. 
Without validity, crowdsourced data adds to the risk of mass unconfirmed need cases which are then overlooked. With this in mind, it seems appropriate to prioritise contexts in which natural, rather than political, disasters are expected or occur frequently. With focus given to specific regions with high natural disaster risks, V\&TCs can begin to target their efforts at a regional level, building relations with local communities and organisations pre-crisis and training civilians to effectively standardise needs requests. In an emergency, these requests can be easily analysed and geo-located by crowdsourced teams. Local connections will also add value to V\&TCs from the perspective of formal responders entering a crisis setting, a technique that HOTOSM have shown to be effective to a degree (Poiani et al. 2016); there are still limitations, and thus still requires further research and analysis as to its effectiveness.

Preparedness also helps build partnerships. V\&TCs and formal organisations must solidify relations and communication procedures before a crisis and incorporate this into regional response plans. The internet has given affected communities a new platform to voice their needs, digital humanitarians are listening and mapping these needs, but unless digital humanitarians and traditional organisations solidify partnerships, the increase in voiced emergency needs only becomes increasing background noise. Traditional humanitarian entities must loosen organisational structures to incorporate volunteer and technical communities. V\&TCs must attempt to standardise data analysis and structure their communication measures to improve connections to responders.

Throughout this research, the communications, data sharing and collaboration that are needed to harness crowdsourced crisis mapping as a response tool have all been hindered by one principle issue, a human one. A lack of preparedness, due in part to V\&TCs focussing on crisis rather than preparation, coupled with fears around the integration of technologies into the humanitarian sector prevents new collaborations and innovation. These are all human emotions that cannot be changed but can be facilitated. Compromise must be met between stakeholders across the digital and humanitarian spheres. As Meier (Interview 2016) highlights on the narrative of crowdsourced crisis mapping, 'this is a human story not a technical one'.

\section{Acknowledgements}

Not applicable.

\section{Funding}

No additional funding was secured for this research.

\section{Authors' contributions}

Divisions of labour in the production of this paper were evenly weighted between the authors. All authors read and approved the final manuscript.

\section{Ethics approval and consent to participate}

This research was carried out following the ethical guidelines as laid down by the School of Arts and Social Sciences, City University London. Informed consent for interviews was gained from all participants and the option to opt-out at any time was granted. All participants are deemed legal adults and are able to consent to their own participation.

\section{Competing interests}

The authors confirm that they have read SpringerOpen's guidance on competing interests and that none of the authors have any competing interests related to this paper.

\section{Publisher's Note}

Springer Nature remains neutral with regard to jurisdictional claims in published maps and institutional affiliations.

Received: 10 September 2018 Accepted: 17 December 2018

Published online: 07 January 2019

\section{References}

Anderson-Tarver C (2015) Crisis mapping the 2010 earthquake in OpenStreetMap Haiti. University of Colorado, Boulder

Ardichvili A, Page V, Wentling T (2003) Motivation and barriers to participation in virtual knowledge-sharing communities of practice. J Knowl Manag 7(1):6477

Gao H, Barbier G, Goolsby R (2011) Harnessing the crowdsourcing power of social media for disaster relief. IEEE Intelligent Systems 26(3):10-14

Bott M, Young G (2012) The role of crowdsourcing for better governance in international development. Praxis: The Fletcher Journal of Human Security 27(1):47-70

Brafman O, Beckstrom R (2006) The starfish and the spider: the unstoppable power of leaderless organisations. Penguin Group, New York

Burns R (2015) Rethinking big data in digital humanitarianism: practices, epistemologies, and social relations. GeoJournal 80(4):477-490

Capelo L, Chang N, Verity A (2012) Guidance for collaborating with volunteer and technical communities. United Nations Office for the Coordination of Humanitarian Affairs, Geneva

Deuze M (2012) Media Life. Polity, Cambridge

DHNetwork. 2016. Coordinators. [online]. Available from: http:// digitalhumanitarians.com/partners. Accessed 4 May 2016

Dodd J (2015) The new reality. Digital for good

FEMA. 2016. Protecting yourself through mitigation. Department of Homeland Security. [Online]. Available from: https://www.fema.gov/protecting-yourselfthrough-mitigation. Accessed 20 June 2016

GFDRR Labs (2011) Volunteer technology communities: open development. The World Bank and GFDRR, Washington DC

Goodchild MF, Glennon JA (2010) Crowdsourcing geographic information for disaster response: a research frontier. Int J Digital Earth 3(3):231-241

Harvard Humanitarian Initiative (2011) Disaster relief 2.0: the future of information sharing in humanitarian emergencies. UN Foundation and Vodafone Foundation Technology Partnership, Washington, D.C. and Berkshire

Heinzelman J, Waters C (2010) Crowdsourcing crisis information in disasteraffected Haiti. Special report. United States Institute of peace, Washington DC

Junqué de Fortuny E, Martens D, Provost F (2013) Predictive modelling with big data: is bigger really better? Big Data 1(4):215-226

Kidd J (2015) Representation. Routledge, Oxon

Meek S, Jackson MJ, Leibovici DG (2014) A flexible framework for assessing the quality of crowdsourced data

Meier P (2015) Digital humanitarians: how BIG DATA changes the face of humanitarian response. CRC Press, Boca Raton

MicroMappers. 2016. About. [online]. Available from: https://micromappers. wordpress.com/about-info/. Accessed 25 Mar 2016

Milner M, Verity A (2013) Collaborative innovation in humanitarian affairs: organization and governance in the era of digital humanitarianism 
Moore R, Bhide N, Verity A (2016) Humanitarian information management failures: survey report. United Nations Office for the Coordination of Humanitarian Affairs, Geneva

Moore R, Verity A (2014) Hashtag standards for emergencies. United Nations Office for the Coordination of Humanitarian Affairs, Geneva

Munro R (2013) Crowdsourcing and the crisis-affected community. Information retrieval 16(2):210-266

Nelson A, Sigal I (2010) Media, information systems and communities: lessons from Haiti. Communicating with Disaster Affected Communities. Internews and John S. and James L. Knight Foundation, Miami

Patrick J (2011) Evaluation insights: Haiti earthquake response: emerging evaluation lessons. OECD, London Available from: https://www.oecd.org/ countries/haiti/50313700.pdf

Plantin J (2014) Participatory mapping: new data, new cartography. ISTE, Ltd, London

Poiani TH, dos Santos Rocha R, Degrossi LC, de Albuquerque JP (2016) Potential of Collaborative Mapping for Disaster Relief: A Case Study of OpenStreetMap in the Nepal Earthquake 2015. 49th Hawaii International Conference on System Sciences (HICSS), Koloa, HI, 2016:188-197.

Ramalingam B (2016) Innovations in the Nepal earthquake response: ten lessons from the DEC response review, Humanitarian Exchange Special Feature. No. 66. Humanitarian Practice Network, London [Online]. Available from: http:// odihpn.org/wp-content/uploads/2016/04/HE-66-Web-Final.pdf

Sancho GR (2014) Networks, insurgencies, and performative politics: a cycle of global indignation. Convergence 20(4):387-401

Scriven K (2016) Humanitarian innovation and the art of the possible, Humanitarian Exchange Special Feature. Humanitarian Practice Network, London No.66. [Online]. Available from: http://odihpn.org/wp-content/ uploads/2016/04/HE-66-Web-Final.pdf

Sharma A (2010) Crowdsourcing critical success factor model: strategies to harness the collective intelligence of the crowd. London School of Economics (LSE), London

Soden R, Palen L (2014) From crowdsourced mapping to community mapping: the post-earthquake work of OpenStreetMap Haiti. In: COOP 2014Proceedings of the 11th International Conference on the Design of Cooperative Systems, 27-30 May 2014, Nice (France). Springer, Cham, pp $311-326$

Specht D (2016) The future of GI in the 3rd sector. In: AGl foresight report 2020. AGl, London, pp 235-239

Stadler F (2012) Between democracy and spectacle: the front-end and back-end of the social web. In: Mandiberg M (ed) The Social Media Reader. New York University Press, New York and London

Stauffacher, D., Hattotuwa, S. and Weekes, B. 2012. The potential and challenges of open data for crisis information management and aid efficiency: a preliminary assessment. Online: ICT4Peace Foundation. [Online]. Available from: http://ict4peace.org/wp-content/uploads/2012/03/The-potential-andchallenges-of-open-data-for-crisis-information-management-and-aidefficiency.pdf. Accessed 31 Aug 2016

Tapscott D, Williams A (2010) MacroWikinomics: rebooting business and the world. Atlantic Books, London

UNGP (2012) Big Data for Development: Challenges and Opportunities. Global Pulse, New York

Verity A, Whipkey K (2015) Humanitarian information management research: how researchers and organisations can work together. UN OCHA Field Information Services, Geneva

Walker BB, Rinner C (2013) A qualitative framework for evaluating participation on the Geoweb. URISA J 25(2):15-24

\section{Submit your manuscript to a SpringerOpen ${ }^{\circ}$ journal and benefit from:}

- Convenient online submission

- Rigorous peer review

- Open access: articles freely available online

- High visibility within the field

- Retaining the copyright to your article

Submit your next manuscript at $>$ springeropen.com 